\title{
NOTAS
}

\section{EFEITO DO CONTROLE DE NEMATÓIDES NA QUALIDADE DA FIBRA DO ALGODOEIRO ( $\left.{ }^{1}\right)$}

\author{
RUBENS RODOLFO ALBUQUERQUE LORDELLO $\left({ }^{2,4}\right)$ \\ e NELSON PAULIERI SABINO $\left(^{3,4}\right.$ )

\section{RESUMO}

Avaliou-se o efeito do tratamento com torta de mamona e com nematicidas sistêmicos (aldicarb, carbofurã, oxamil e sulfona de aldicarb), na qualidade das fibras do algodoeiro (Gossypium hirsutum cv. IAC 17) cultivado em área infestada por Meloidogyne incognita, Pratylenchus brachyurus, Helicotylenchus dihysteroides e Xiphinema sp., no nunicípio de Paranapanema, no Estado de São Paulo. As características afetadas foram: o comprimento das fibras, no qual só o carbofurã produziu aumento significativo; a resistência das fibras, que aumentou com os tratamentos torta de mamona e aldicarb; e a maturidade das fibras, onde, com exceção do oxamil, todos os tratamentos foram superiores à testemunha. As características de uniformidade e índice de finura das fibras não diferiram da testemunha em nenhum dos tratamentos.

Termos de indexação: algodão, fibra, nematóides, nematicidas, controle.

\section{INTRODUÇÃO}

Em 1889, Atkinson relacionou o algodoeiro como um dos 36 hospedeiros do gênero Meloidogyne, na primeira notícia da associação entre ne-

( ${ }^{1}$ ) Apresentada na IV Reuniāo Brasileira de Nematologia, realizada em São Paulo, de 16 a 20 de julho đe 1979. Recebida para publicação em 23 de março de 1984.

( ${ }^{2}$ ) Seção de Microbiologia Fitotécnica, Instituto Agronômico (IAC), Caixa Postal 28, $13100 \mathrm{Cam}$ pinas, SP.

$\left(\begin{array}{l}3 \\ 4\end{array}\right)$ Seção de Tecnologia de Fibras, IAC.

(4) Com bolsa de suplementação do CNPq. 
matóides e o algodoeiro (SASSER, 1972). Após esse trabalho pioneiro, os nematóides progressivamente passaram a ser reconhecidos como importantes inimigos da cultura.

A literatura é rica em relatos de perdas causadas por nematóides ao algodoeiro, merecendo destaque o de GOOD \& STEELE (1958), que verificaram o aumento de produção de mais de sete vezes em solo infestado por Belonolaimus sp. após o tratamento com nematicidas fumigantes. No Brasil, quem primeiro verificou o parasitismo do algodoeiro por nematóides foi LORDELLO (1953), que, posteriormente, apresentou trabalhos envolvendo outros aspectos dessa associação (1981).

Em relação às características tecnológicas das fibras, JONES et alii (1959) verificaram, em condiçôes de campo, que Rotylenchulus reniformis prejudicou a maturidade e, em alguns anos, a porcentagem de fibra. Tamanho das sementes, comprimento, resistência e finura da.fibra, mostraram pouco ou nenhum efeito do parasitismo dessa espécie.

Com vistas à avaliação dos efeitos do controle de nematóides na produção e em características tecnológicas da fibra do algodoeiro, foi conduzido o presente experimento.

\section{MATERIAL E MÉTODOS}

O experimento foi instalado na fazenda Holambra II, em Paranapanema (SP), em 3/11/1978, em área de solo arenoso, utilizando-se sementes de algodoeiro (Gossypium hirsutum L. cv. IAC 17). A identificação dos nematóides extraídos de uma amostra de terra, pelo método da centrífuga, mostrou a presença das espécies: Pratylenchus brachyurus (Godfrey, 1929) Filipjev \& Stekhoven, 1941; Helicotylenchus dihysteroides Siddiqi, 1972; Meloidogyne incognita (Kofoid \& White, 1919) Chitwood, 1949 e Xiphinema sp., das quais foram obtidos, respectivamente, 60, 210,60 e 60 exemplares por 200 gramas de terra. $M$. incognita foi identificada mediante fêmeas obtidas de raizes de algodoeiro.

O delineamento experimental adotado foi blocos casualizados, com seis tratamentos e oito repetiçôes. Quatro linhas de $5 \mathrm{~m}$ de comprimento constituíram as parcelas, sendo consideradas úteis as duas centrais. O espaçamento foi um metro entre linhas, deixando-se, em média, 35 plantas por linha após a raleação.

Para o controle dos nematóides, foram aplicados os tratamentos: A) aldicarb (Temik 10G), 2kg de princípio ativo/hectare; B) sulfona de aldicarb (Standak $75 \mathrm{PM}$ ), $4 \mathrm{~kg}$ p.a./100kg de sementes; C) carbofurã (Furadan $5 \mathrm{G}$ ), $2 \mathrm{~kg}$ p.a./ha; D) oxamil (Vydate G), $2 \mathrm{~kg}$ p.a./hectare; E) torta de mamona, 
$500 \mathrm{~kg} /$ ha; e F) testemunha. Os tratamentos A, C, D e E foram aplicados no sulco, por ocasião do plantio, e o $\mathrm{B}$, misturado às sementes no dia anterior.

Todas as parcelas foram conduzidas com as práticas fitotécnicas usuais na cultura e receberam a mesma quantidade de fertilizantes da fórmula recomendada para a gleba, de acordo com o resultado da análise da terra. $\mathrm{O}$ controle químico das pragas foi efetuado com os produtos adotados na região.

Foram utilizados quarenta capulhos por parcela, colhidos do terço médio das plantas, para a análise das seguintes características tecnológicas das fibras: comprimento, uniformidade de comprimento, finura (Micronaire), resistência e maturidade.

\section{RESULTADOS E DISCUSSÃO}

Neste trabalho foram estudadas somente as características tecnológicas das fibras, uma vez que o ensaio foi prejudicado pela ocorrência de erosão, causada pelas águas de chuva, que destruiu parcialmente quatro blocos.

As médias dos resultados obtidos se encontram no quadro 1, com as respectivas análises estat ísticas. Para os parâmetros estudados, a análise da

QUADRO 1 - Valores médios das características tecnológicas das fibras de algodoeiro, do experimento de controle de nematójdes em Paranapanema (SP)

\begin{tabular}{|c|c|c|c|c|c|}
\hline Tratamentos & $\begin{array}{c}\text { Comprimento } \\
\text { mm }\end{array}$ & $\begin{array}{l}\text { Uniformidade } \\
\qquad \%\end{array}$ & $\begin{array}{l}\text { Indice de } \\
\text { finura }\end{array}$ & $\begin{array}{c}\text { Resistencia } \\
\text { Pressley } \\
\text { g/Tex }\end{array}$ & $\begin{array}{c}\text { Maturidade } \\
\%\end{array}$ \\
\hline $\begin{array}{l}\text { Aldicarb } \\
2 \mathrm{~kg} \text { i.a. } / \mathrm{ha}\end{array}$ & $26,63 \mathrm{ab}\left({ }^{1}\right)$ & 46,90 & 4,68 & $18,67 a b$ & $57,68 a$ \\
\hline $\begin{array}{l}\text { Sulfona de aldicarb } \\
\quad 4 \mathrm{~kg} \text { i.a. } / 100 \mathrm{~kg} \text { de sementes }\end{array}$ & $26,69 \mathrm{ab}$ & 46,07 & 4,75 & $18,55 \mathrm{abc}$ & $58,08 a$ \\
\hline $\begin{array}{l}\text { Carbofura } \\
2 \mathrm{~kg} \text { i.a. } / \mathrm{ha}\end{array}$ & $27,25 a$ & 46,67 & 4,71 & $18,27 \mathrm{abc}$ & $58,84 a$ \\
\hline $\begin{array}{l}\text { Oxarnil } \\
2 \mathrm{kgg} \text { i.a./ha }\end{array}$ & $26,57 b$ & 46,13 & 4,72 & $17,93 \mathrm{bc}$ & $56,63 \mathrm{ab}$ \\
\hline $\begin{array}{l}\text { Torta de rnamona } \\
500 \mathrm{~kg} / \mathrm{ha}\end{array}$ & $26,75 a b$ & 46,46 & 4,87 & $19,11 \mathrm{a}$ & $57,29 a$ \\
\hline Testemunha & $26,35 \mathrm{~b}$ & 45,82 & 4,67 & $17,64 c$ & $52,09 \mathrm{~b}$ \\
\hline $\begin{array}{l}\text { CV (\%) } \\
\text { Tukey (5\%) } \\
\text { Valores de "F" }\end{array}$ & $\begin{array}{l}1,67 \\
0.67 \\
3,69 * *\end{array}$ & $\begin{array}{l}2,18 \\
- \\
1,44\end{array}$ & $\begin{array}{l}5,65 \\
0,26\end{array}$ & $\begin{array}{l}3,49 \\
0,96 \\
5,26 \text { ** }\end{array}$ & $\begin{array}{l}5,82 \\
4,98 \\
4,24^{* *}\end{array}$ \\
\hline
\end{tabular}

(') Letras iguais simbolizam mesma classe estatistica pelo teste de Tukey a $5 \%$. 
variância revelou que o controle dos nematóides afetou o comprimento, a resistência e a maturidade das fibras.

Em relação aos comprimento das fibras, apenas o carbofurã produziu aumento significativo, não diferindo os demais tratamentos da testemunha. A resistência das fibras foi maior para os tratamentos torta de mamona e aldicarb, não sendo significativamente diferente para os demais. Quanto à maturidade das fibras, com exceção do oxamil, todos os tratamentos foram estatisticamente superiores à testemunha.

As características de uniformidade e índice de finura das fibras não foram significativamente diferentes da testemunha para nenhum dos tratamentos.

Dentre os nematicidas utilizados, o oxamil foi o único que não apresentou diferença estatística significativa, em relação à testemunha, em nenhuma das características das fibras avaliadas.

\section{CONCLUSÖES}

Os resultados obtidos corroboram os estudos de JONES et alii (1959), que relataram ter a infestação de nematóides prejudicado a maturidade das fibras. Eles não detectaram as diferenças aqui verificadas quanto às características de comprimento e resistência das fibras, diferenças essas provavelmente devidas ao tipo de solo, às condições climáticas e, sobretudo, às espécies e populaçסes de nematóides envolvidas.

A análise dos resultados permite concluir que:

a) A aplicação da torta de mamona ou dos nematicidas sistêmicos (carbofurã, aldicarb e sulfona de aldicarb) melhorou a qualidade das fibras do algodoeiro.

b) $\mathrm{O}$ efeito dos tratamentos sobre as características de uniformidade e índice de finura (Micronaire) foi desprezível.

\section{AGRADECIMENTOS}

Os autores agradecem ao Dr. Ailton R. Monteiro a identificação específica de $H$. dihysteroides, e ao Dr. Antonio Carlos Pimentel Wutke a crítica do manuscrito. 


\title{
SUMMARY \\ EFFECT OF NEMATODE CONTROL ON FIBER PROPERTIES \\ OF UPLAND COTTON
}

\begin{abstract}
The effect of nematode control using castor bean cake and systemic nematicide treatments (Aldicarb, Carbofuran, Oxamyl and Sulfon Aldicarb), on the fiber properties of upland cotton (Gossypium hirsutum cr. IAC 17) was evaluated. The crop was grown in Paranapanema - SP, Brazil, in a field infested with Meloidogyne incognita, Pratylenchus brachyurus, Helicotylenchus dihysteroides and Xiphinema sp. The properties affected were: fiber length, which improved only with Carbofuran; fiber strength, that improved with the treatments castor bean cake and Aldicarb; and fiber maturity, in which all treatments showed superior results than the check, except Oxamyl. No treatment effects on fiber fineness and uniformity were observed.
\end{abstract}

Index terms: cotton, fiber, nematodes, nematicides, control.

\section{REFERÊNCIAS BIBLIOGRÁFICAS}

GOOD, J.M. \& STEELE, A.E. Control of sting nematodes for two growing seasons by soil fumigation. Plant Disease Reporter, 42(12):1364-1367, 1958.

JONES, J.E.; NEWSOM, L.D. \& FINLEY, E.L. Effect of the reniform nematode on yield, plant characters, and fiber properties of upland cotton. Agronomy Journal, 51(6):353-356, 1959.

LORDELLO, L.G.E. Contribuição ao conhecimento dos nematóides do solo de algumas regiōes do Estado de São Paulo. Piracicaba, Escola Superior de Agricultura "Luiz de Queiroz", 1953. 75p. Tese (Doutoramento) $314 \mathrm{p}$.

SASSER, J.N. Nematode diseases of cotton. In: WEBSTER, J.M., ed. Economic Nematology. London, New York, Academic Press, 1972. p.268284. 